\title{
Arte y nación. Escultura pública en Lima
}

RECIBIDO: 05/09/2017

APROBADO: 04/12/2017.

Virgilio Freddy Cabanillas Delgadillo

Universidad Nacional Mayor de San Marcos

< peruanticuario@yahoo.es>

\section{RESUMEN}

Estudiamos la escultura pública de la ciudad de Lima. Gran parte de la historia nacional está contada en dichas obras de arte: Manco Cápac, Francisco Pizarro, José de San Martín, Simón Bolívar, Ramón Castilla, José Gálvez y la Victoria del 2 de Mayo, Antonio Raimondi, Miguel Grau y Francisco Bolognesi. Las piezas han sido analizadas con métodos de la Historia del Arte (análisis formal, iconografía) en diálogo con disciplinas de las Ciencias Sociales. En este trabajo — avance de nuestra tesis doctoral en Historia del Arte- nos detenemos en un caso emblemático: el monumento al héroe deArica.

Palabras Clave: arte y nación; escultura pública; iconografía; patrimonio; Plaza Bolognesi.

\section{Art and Nation. Public sculpture in Lima}

\section{ABSTRACT}

We studied the public sculpture of Lima city. A large proportion of the national history is told in these pieces of art: Manco Cápac, Francisco Pizarro, José de San Martín, Simón Bolívar, Ramón Castilla, José Gálvez and the Victory on May 2, Antonio Raimondi, Miguel Grau and Francisco Bolognesi. The pieces have been analyzed with methods of the Art History (formal analysis, iconography) together with social science disciplines. In this work — draft of our doctoral thesis in Art History— we focus on an emblematic case: the monument to the hero of Arica.

KeYwords: Art and nation; public sculpture; iconography, Heritage; Plaza Bolognesi. 
as esculturas urbanas sirven como hitos en las ciudades, definen espacios reales y simbólicos, se emplean en la educación cívica de la población y son testimonios históricos visibles que ayudan a remarcar la identidad y los valores patrióticos y ciudadanos. Sin duda, todo ello responde a la orientación que le quieran dar las élites en el poder. Por ello es necesario historiarlas, demostrar su validez como obras de arte en base a sus valores plásticos, explicar sus contenidos y promover su conservación.

\section{Monumento al coronel Francisco Bolognesi}

La iniciativa para levantar un monumento al héroe de Arica partió de los escolares del Liceo Internacional de Lima, dirigido por Luis Gálvez. Pronto se sumaron otros estudiantes, la ciudadanía y las autoridades. Así se gestó un concurso internacional que fue ganado por el escultor español Agustín Querol (1860-1909). El monumento se inauguró el 6 de noviembre de 1905.

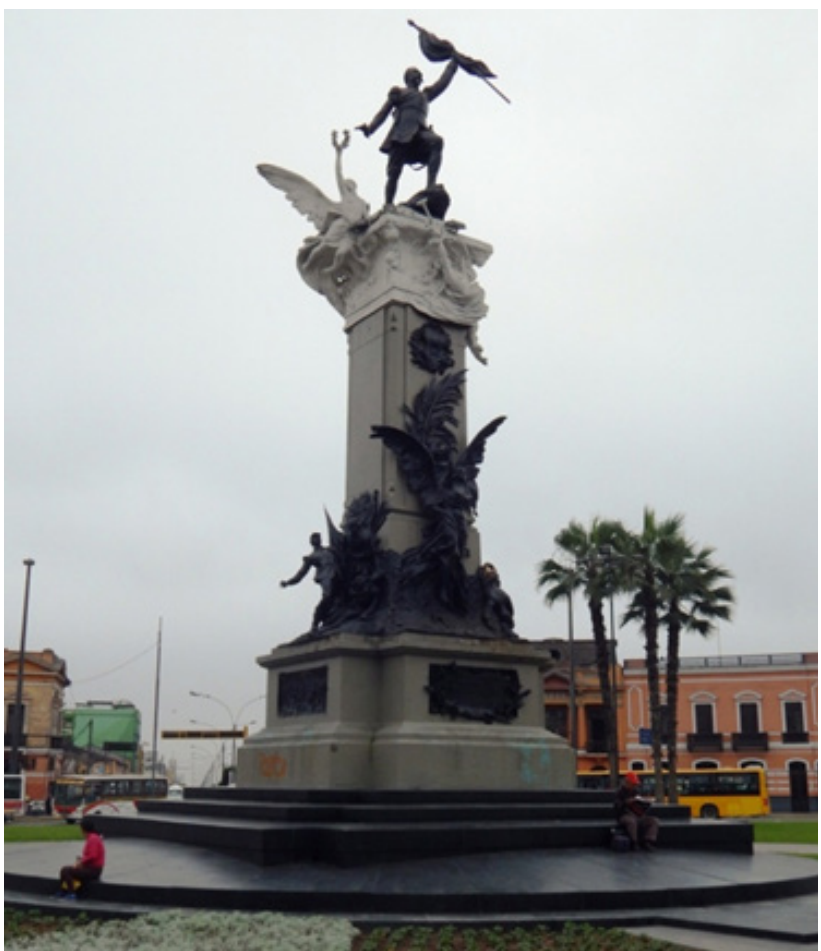

Figura 1. Monumento a Bolognesi. Estado actual. Fotografía del autor (2013).

Pero la estatua principal fue cambiada en 1954 por otra del escultor peruano Artemio Ocańa (1894-1980) La extraordinaria pieza original de Querol se conserva en la Fortaleza del Real Felipe.

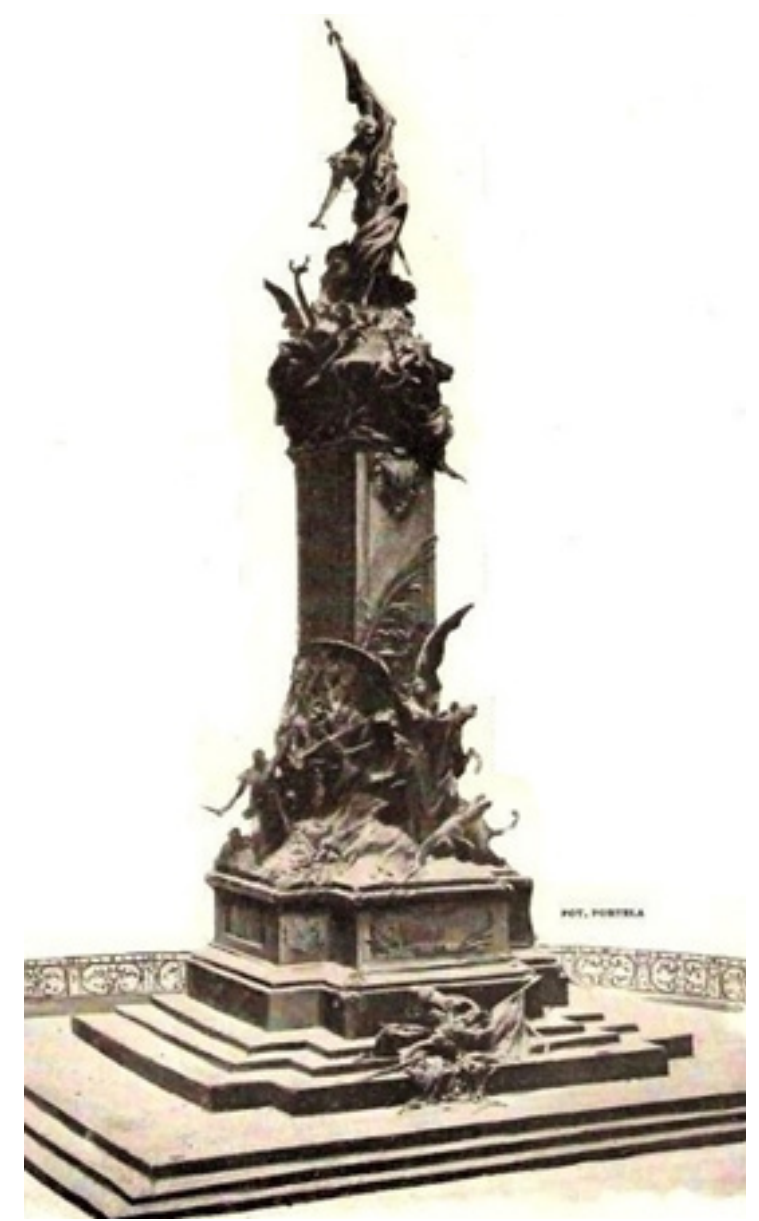

Figura 2. Publicación española (1902) que celebra el triunfo de Querol en el concurso. La maqueta ganadora pasó por algunos cambios como se aprecia en el basamento. Además no se hicieron la reja y la forma escultórica de la parte delantera inferior.

https://www.todocoleccion.net/coleccionismo-revistas-periodicos/revistaano-1902-agustin-querol-monumento-bolognesi-arenys-mar-granjaparaiso-avicultura ×31278452

\section{Análisis}

La obra es un grupo escultórico urbano de volumen abierto y bulto redondo que ofrece a la contemplación una multiplicidad de puntos de vista. Es un esquema compositivo piramidal —un triángulo isóscelesconformado por las siguientes secciones:

- Basamento inferior de piedra.

- Pedestal de piedra con zócalo, dado y cornisa. Sirve de soporte a cuatro relieves de bronce.

- Pilar de piedra con capitel de mármol. Alrededor de su base se organizan ocho figuras de bronce: seis de forma humana, un caballo y una figura humana alada. En el capitel hay dos figuras humanas alegóricas de mármol. 
- Corona el conjunto una escultura de bronce de forma humana.

El conjunto es dinámico por el diálogo entre líneas horizontales, verticales y diagonales que se contrastan en su desarrollo.

Sobre un basamento de cinco escalones - los dos primeros circulares y los tres siguientes cruciformesse ubica el pedestal de planta en forma de cruz, compuesto por un zócalo, dado y cornisa. En las cuatro caras del dado hay placas de bronce con relieves e inscripciones:

1. Este: Sobre un recuadro horizontal hay una cartela adornada con laureles y palmas. El texto dice: «LA NACIÓN A FRANCISCO BOLOGNESI Y SUS COMPAÑEROS DE ARICA EN 7 DE JUNIO DE 1880».

2. Oeste: Sobre un recuadro horizontal hay una cartela adornada con guirnaldas, contiene la siguiente inscripción: "JEFES QUE FORMARON EL CONSEJO DE GUERRA QUE DETERMINÓ LA DEFENSA DE LA PLAZA DE ARICA POR UNANIMIDAD DE VOTOS EL 28 DE MAYO DE 1880 A LAS 8 DE LA NOCHE». Sigue la lista que encabeza Francisco Bolognesi.

3. Norte: Escena inspirada en el óleo La respuesta de Juan Lepiani.

En ambos casos hay dieciséis personas. La composición es similar pero la diferencia está en el ritmo. Calma en la pintura y agitación en el relieve. En ambos casos, Bolognesi señala al suelo para enfatizar su negativa a rendirse mientras apoya la mano izquierda en la empuñadura de la espada. Pero su protagonismo es más marcado en el diseño de Querol. Con su cabeza erguida y el brazo izquierdo formando ángulo, se diferencia del Bolognesi de Lepiani que calmadamente rechaza la deshonrosa oferta. Igualmente, el emisario chileno Juan de la Cruz Salvo que se encuentra al lado izquierdo —en la puerta — tiene más movimiento en la propuesta queroliana.

El Cnel. José Joaquín Inclán se ubica en ambos casos al lado de la mesa; pero poco creíble es la postura afectada que asume en el relieve de Querol, a diferencia de la pintura, en la que escucha atentamente la propuesta enemiga. También es notoria la marcada indignación de los oficiales peruanos -especialmente el grupo que está detrás de Bolognesi-que clavan sus miradas en el mayor chileno. En cambio, en la obra de Lepiani todos escuchan con serenidad las palabras de Juan de la Cruz Salvo.

4. Sur: Escena inspirada en el óleo El último cartucho de Juan Lepiani.

La composición es en esencia la misma, pero nuevamente Querol le ha impreso un ritmo más agitado a la representación.

Una diferencia notable está en la figura del Capitán de Navío Juan Guillermo Moore. Su cadáver se encuentra un plano antes que la figura de Bolognesi, en el relieve su rodilla izquierda forma un ángulo más aguzado que en la pintura.

$\mathrm{Al}$ extremo derecho hay un soldado chileno en primer plano, listo para golpear a alguien que no vemos. En el relieve, Querol le ha dotado de otro ritmo curvando su cuerpo de manera un poco artificiosa.

Con excepción de Bolognesi y los marinos de la Independencia, no sería posible diferenciar a los soldados de ambos bandos si no fuera por el conocimiento previo de la pintura que se conserva en el Museo de los Combatientes del Morro de Arica.

Volviendo al conjunto, sobre el pedestal se alza un pilar, estructura que sirve de apoyo a las figuras escultóricas trabajadas en bronce. Son piezas dependientes de la estructura arquitectónica que las soporta, fueron pensadas para la visión frontal y lateral. Alrededor de la basa se desarrolla una recargada iconografía:

1. Al oriente: una estatua figurativa de volumen abierto que representa a una alegoría femenina alada que alza el vuelo. En el diseño de la pieza el artista ha empleado líneas verticales (brazo derecho y piernas), diagonales (pliegues de la ropa) y curvas (borde superior de las alas). La luz incide de manera contrastada, generando efectos de claroscuro.

La figura femenina está vendada. Mientras se eleva, señala con la mano derecha hacia lo alto, a la figura principal que está en la cima (o al cielo). Es notable el detalle de sus pies suspendidos en el aire - solo se aprecia uno, el otro es cubierto por la vestimenta - que vencen la gravedad para elevarse al firmamento. La pierna derecha se adelanta en acentuado escorzo y la parte inferior del vestido se mueve hacia atrás siguiendo la dirección del brazo izquierdo. Se observa el uso de la técnica de los 
pańos mojados en el vientre. Las superficies lisas y rugosas se distribuyen por la figura según lo requiere el detalle representado; generan contrastes marcados, por ejemplo entre la piel de la mujer y otros sectores como las telas arrugadas, las alas o el fondo que hace de paisaje. Pero las alas no han sido trabajadas con meticulosidad realista, el escultor simula las plumas con una superficie texturada, que a la distancia funciona bien.

Querol ya había empleado esta figura en una obra anterior, como alegoría de la fe ${ }^{1}$.

Sobre el muro -y elevándose por encima de la alegoría femenina- hay una enorme rama de palma curvada a punto de tocar la figura del escudo nacional. Dibuja una curva paralela a la que configura el ala izquierda.

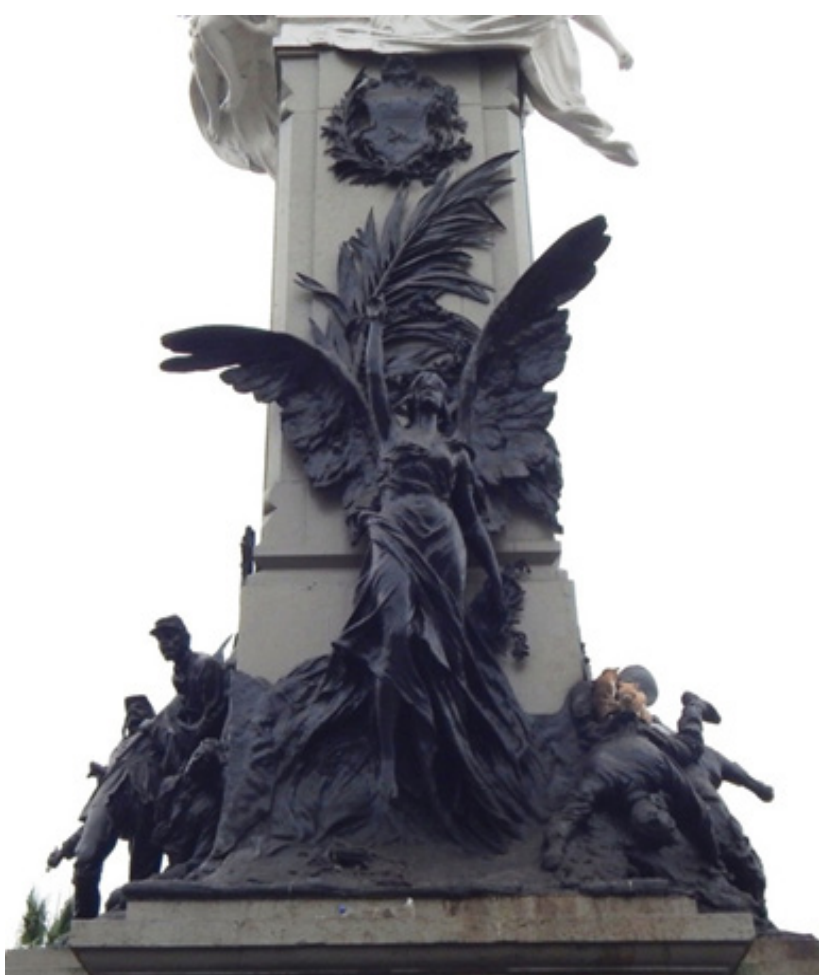

Figura 3. Fotografía del autor (2013).

2. En la cara opuesta — al oeste - hay una mujer de espaldas al espectador. Es una estatua figurativa naturalista de volumen abierto. Alegoría de la Historia $^{2}$ que se lamenta mientras anota — con la mano derecha- en el muro el ańo aciago de la

1 Nos referimos a la figura alada, vendada y señalando al Cielo que Querol hizo en La Habana en 1897.

2 Entrevista a Daniel Tipian: Monumento de Querol a Francisco Bolognesi. http://programaumbrales.blogspot.pe/2016/06/entrevistadaniel-tipian-monumento-de.html batalla: 1880. La cifra está acompańada por una rama de palma. El rostro de la mujer doliente se oculta en el ángulo que forma su brazo izquierdo. La luz incide de manera contrastada, generando efectos de claroscuro. Las superficies lisas y rugosas se distribuyen por la figura según lo requiere el detalle representado; generan contrastes marcados, por ejemplo entre la piel de la mujer y otros sectores como las telas y el área texturada que sirve de paisaje de fondo.

Hay un movimiento Art Nouveau acentuado por la curva continua que empieza en la pierna izquierda dirigida hacia atrás, sigue por las formas naturales del cuerpo femenino, avanza por la tela que se eleva hacia la derecha y culmina en la rama de palma sobre el año ya indicado. A la izquierda de la mujer hay un combatiente peruano muerto que aún se aferra a su fusil. El quepí se encuentra a un lado y se observa una rama de laurel en la mano derecha del hombre. La caída escalonada del vestido de la mujer orienta nuestra mirada hacia al soldado que yace en el suelo. Al lado derecho de la alegoría femenina se observa una pieza de artillería en el suelo.

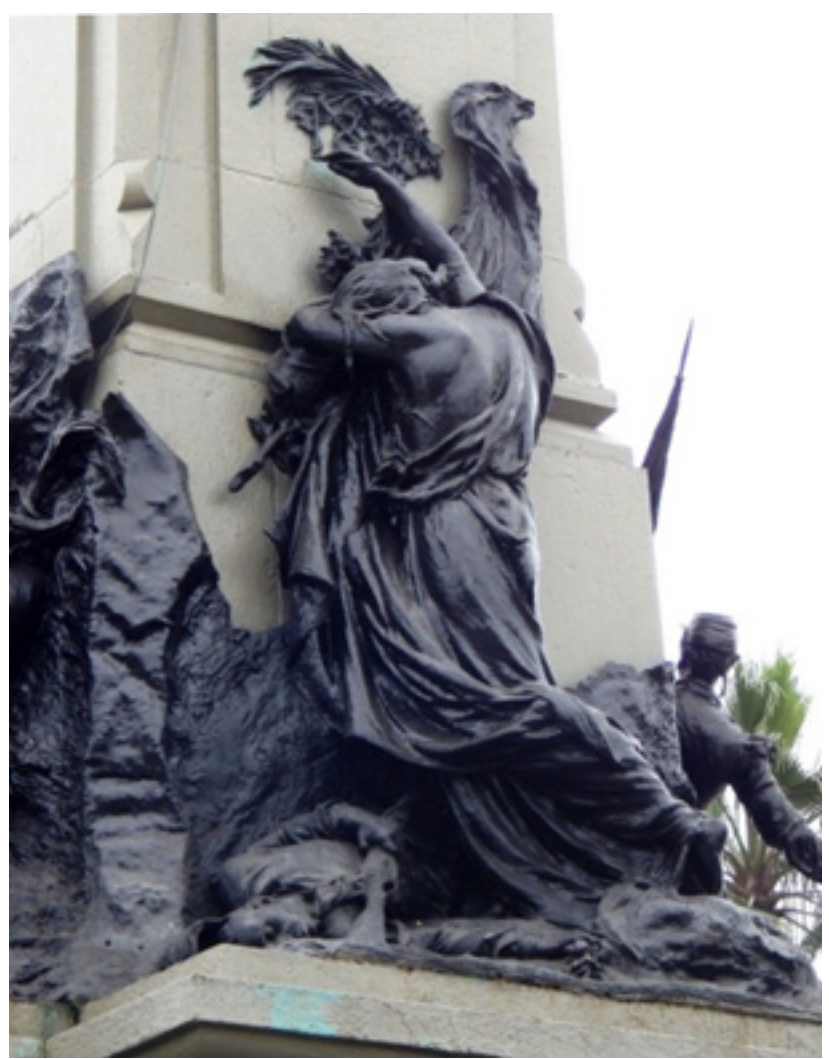

Figura 4. Fotografía del autor (2013). 
3. En las caras norte y sur del pedestal se desarrollan aspectos de la batalla.

Lado norte: Teniendo como trama geométrica un triángulo rectángulo, se organizan dos figuras, un hombre y un caballo. La representación es figurativa naturalista y de volumen abierto. El triángulo se configura por el borde izquierdo del alto relieve (cateto) y el cuerpo del combatiente colocado en diagonal (hipotenusa). Un jinete -que no ha soltado el revólver-y su caballo acaban de caer entre las rocas; el cuerpo retorcido del equino, sus patas rígidas y el cadáver de su amo configuran la dramática escena. La curva acentuada del cuello del caballo orienta nuestra mirada hacia el héroe derribado, para salir luego - hacia abajo- por la línea que pasa entre el brazo izquierdo y el borde superior de la cabeza equina. La luz incide de manera contrastada, generando efectos de claroscuro. Las superficies lisas y rugosas se distribuyen por la figura según lo requiere el detalle representado; generan contrastes marcados, por ejemplo entre la piel del caballo y otros sectores como la vestimenta del hombre y el área texturada que alude al paisaje rocoso. Es la representación del acto heroico de Alfonso Ugarte. Las patas dobladas del caballo recuerdan a los cuatro Pegasos de Querol que se encuentran en el atrio del Palacio de Bellas Artes de Ciudad de México (1912).

4. En el lado sur del pedestal están los defensores del morro en el momento final de la batalla. La representación es figurativa naturalista y de volumen abierto. Despierta interés el contraste entre el alto relieve - las tres estatuas de soldadosy el bajo relieve que muestra un paisaje de fondo con soldados en pleno fragor del combate.

Esta composición implica una trama geométrica compleja con líneas que apuntan en diferentes direcciones -remarcando la violencia del momento- y curvas que definen el ritmo dinámico de la escena. Se distingue claramente dos triángulos superpuestos y contrapuestos. La luz incide de manera contrastada, generando efectos de claroscuro. Predominan las superficies rugosas. En primer plano la estatua de un oficial abanderado que camina curvando su cuerpo hacia atrás como esquivando las balas enemigas. Su figura se ubica en un triángulo rectángulo imaginario. Al igual que sus compañeros, viste casaca, pantalón, bota y quepí. Porta una pistola al cinto, empuña un sable con la diestra y sostiene una bandera con la izquierda, la misma que pega contra su cuerpo a la altura de su corazón. En segundo término hay dos soldados más — se ordenan en otro triángulo rectángulo imaginario - uno cae herido y se lleva la mano al pecho, el rifle está a punto de desprenderse de su mano izquierda; el otro avanza sosteniendo su arma con ambas manos y buscando al enemigo. Detrás de los tres hay los restos de una pieza de artillería.

Sobre la pared vemos un bajo relieve que sirve de tercer plano a la escena. Muestra a varios combatientes gesticulando en medio del fragor de la pelea, brazos en movimiento y puntas de espadas y bayonetas.

En este conjunto hay varias mutilaciones en el bronce.

Ahora desplazamos la vista hacia la parte alta del monumento. El capitel de mármol está decorado con motivos fitomorfos y en él se encaraman dos alegorías femeninas, son representaciones figurativas, naturalistas, de volumen abierto y dependientes de la estructura arquitectónica que las soporta.

Ambas lucen vestidos que no llegan a cubrir los pechos y las piernas; una de ellas — en la cara oriente- se eleva por la izquierda del héroe y toca una larga corneta - decorada con un lazo- que sostiene con la diestra. El instrumento musical se asocia iconográficamente con la Fama. Con la otra mano se agarra de una de las ramas que hay en el capitel. Su larga cabellera es movida por el viento y la ropa se agita a ambos lados de su cuerpo. La otra alegoría se eleva - en la cara sur-e intenta colocar una corona de laurel en la cabeza del héroe.Esta figura es alada, aunque igual se apoya con la mano izquierda en el capitel. Su larga vestidura se prolonga hasta la cara oeste del pedestal. Una lámina de 1905 titula a este conjunto del capitel con el nombre de La Gloria ${ }^{3}$.

En la cumbre del monumento se encuentra la escultura en bronce que representa al Cnel. Bolognesi. La pieza original es una figura de cuerpo entero y de pie, de volumen abierto y movimiento congelado. Es una escultura de bulto redondo, independiente de la estructura arquitectónica que la soporta.

3 https://www.todocoleccion.net/coleccionismo-revistas-periodicos/ agustin-querol-1905-capitel-hoja-revista-x25859703\#sobre_el_lote 


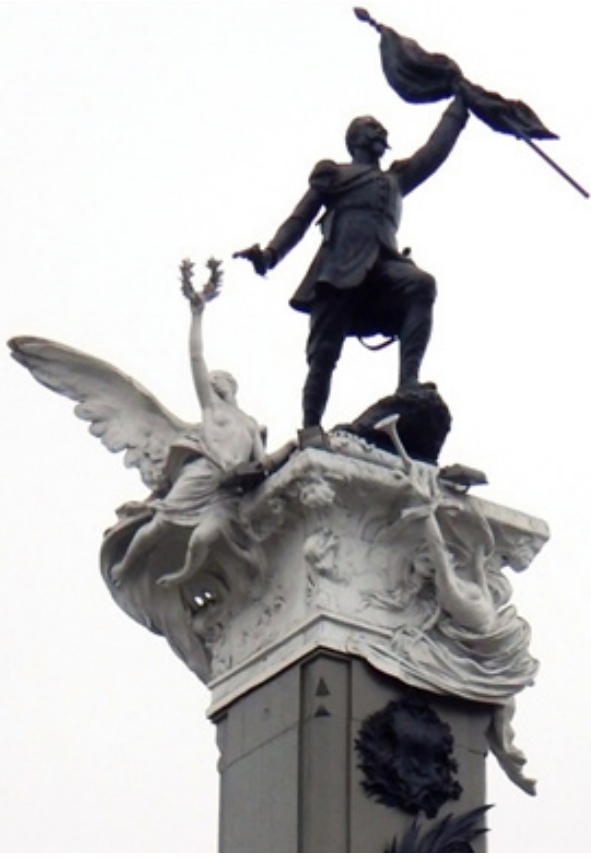

Figura 5. Fotografía del autor (2015).

La composición es piramidal o triangular, forma remarcada por el asta de la bandera. Muestra al héroe herido de muerte, ensimismado en su sacrifico consciente, abrazando el símbolo patrio y sin soltar la pistola con la que ha disparado el último cartucho. La luz incide de manera contrastada, generando efectos de claroscuro. Predominan las superficies rugosas tanto en los dobleces de la bandera como en la vestimenta. La tensión del momento se expresa en detalles como el movimiento agitado de la enseña replegada formando curvas, igualmente en las arrugas del traje militar.

El asta lleva nuestra mirada hacia la mano izquierda — sobre el pecho-y la cabeza del héroe; luego somos atraídos por la mano derecha, donde se encuentra el simbólico revolver que hace alusión a la celebrada frase de Bolognesi. Hay dos puntos de fuga notorios en esta pieza, uno de ellos es precisamente el revólver y el otro la punta del asta, que se dirige hacia una dimensión trascendente.

El héroe trastabilla como consecuencia del disparo enemigo, pero se mantiene en pie sobre un montículo. Con la mano derecha sostiene el arma, aunque el brazo está caído y la pistola ya no apunta al enemigo. Con su brazo izquierdo abraza la agitada bandera, la tela y el hombre están indisolublemente unidos mientras la mano toca el pecho herido. Bolognesi y la bandera son una sola entidad, él carga sobre sí a la Patria en su hora trágica. La cabeza del héroe se inclina, como si la batalla y el proceso natural de la muerte se hubieran detenido un momento para que el coronel reflexionara sobre el cumplimiento de su promesa de sacrificio por la Patria. Es una representación alegórica.

El héroe luce botas y chaqueta militar con charreteras y dos cordones en el lado derecho; del lado izquierdo de su cuerpo cuelgan el tahalí y la funda de la espada. En las botas, Querol nos trasmite la doble sensación de firmeza y flexibilidad de los implementos de cuero al alternar la rigidez del calzado con las arrugas que se observan en su superficie. A sus pies hay una espada rota y los restos de una pieza de artillería.

Como observa Rodrigo Gutiérrez (2003b, p. 373), Querol ya había trabajado la idea de representar a los personajes heroicos en el momento de su muerte, como se aprecia en el Monumento a los Bomberos (La Habana, 1897) y el Monumento a los Mártires de la Religión y la Patria (Zaragoza, 1904).

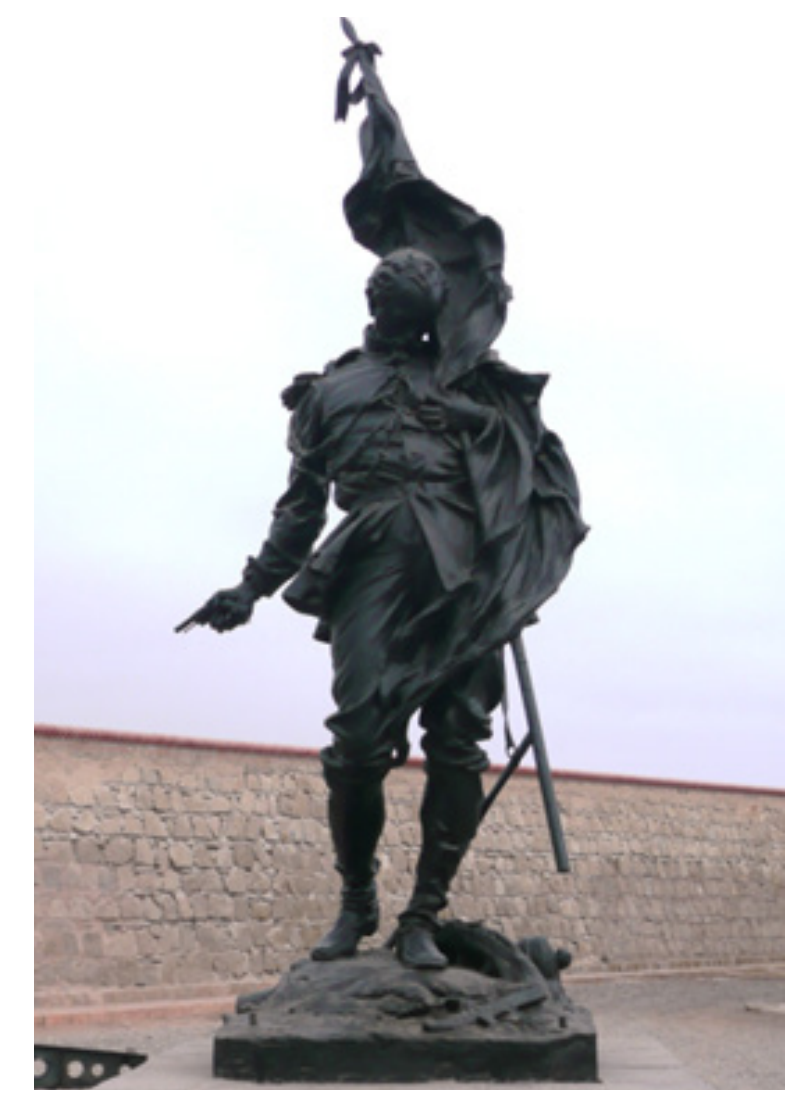

Figura 6. Estatua original del monumento a Bolognesi. Museo del Ejército, Fortaleza del Real Felipe. Fotografía del autor (2015).

La idea del pilar con la estatua principal en su cumbre y un grupo de figuras en su inicio fue recurrente en la obra de Querol. El diseño se aprecia en el Monumento a la Carta Magna y las cuatro regiones argentinas en 
Figura 7. Detalle del Monumento a los bomberos. http:// hojassdeprensa. blogspot.pe/2012/05/ el-mausoleo-losbomberos-delcementerio.html

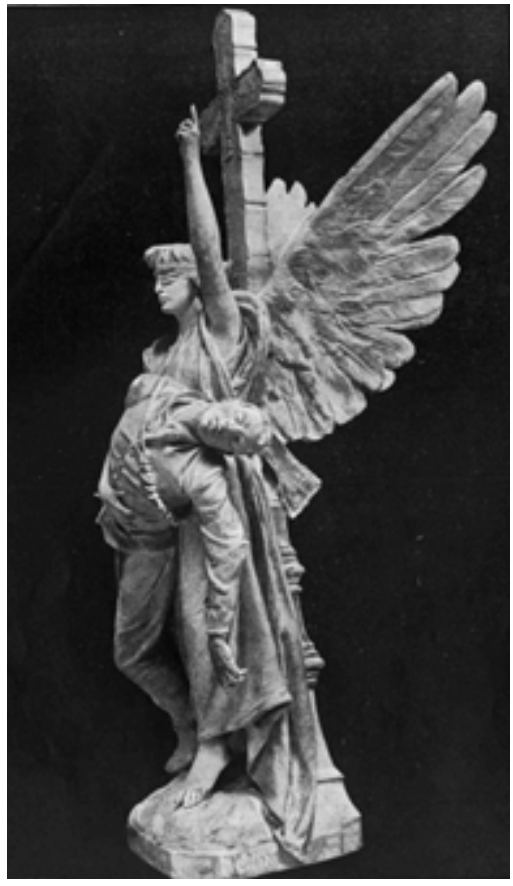

Buenos Aires, también llamado «Monumento de los españoles» (que solo se pudo inaugurar varios años de la muerte del escultor), el Monumento a Quevedo (1902) en Madrid y el Monumento a los sitios de Zaragoza (1908) en dicha ciudad. En el primero y en el último de los mencionados, el grupo de figuras de la parte baja se mueve agitadamente, de manera similar a la escultura limeña.

Igualmente, la profusión de alegorías aladas, los símbolos de gloria que son elevados en dirección a la figura principal en la cima y la combinación de volúmenes con relieves que se apoyan en el pilar, se reitera en los tres monumentos mencionados.

La alegoría alada que señala al cielo con una mano está presente en la cima del Monumento a los bomberos (1897) en La Habana —es la Fe que conduce a la inmortalidad a las víctimas del deber-y en el Monumento a los Mártires de la religión y de la patria (1904) en Zaragoza —el ángel que sostiene al combatiente y está a punto de conducirlo al Cielo-; aunque en estos casos es el brazo izquierdo. Ambas figuras sostienen a un héroe herido, que ligeramente recuerdan a la estatua de Bolognesi, sobre todo en la escultura de 1904, específicamente la parte de las piernas. Hay que agregar que la alegoría de la Fe en La Habana (1897) tiene los ojos vendados, idea que Querol volvió a ensayar en el monumento a Bolognesi. El ángel de Zaragoza no está vendado pero tiene los ojos cerrados, lo que nos hace pensar que también se trata de la $\mathrm{Fe}$
Y el combatiente muerto a los pies de la Patria —en Lima - fue reiterado en el Monumento a los sitios de Zaragoza, esta vez a los pies de la alegoría de la ciudad.

Pero las similitudes más notorias se encuentran en el proyecto que Querol presentó en el concurso para el monumento a Alfonso XII en Madrid (1901). Esencialmente es lo mismo que diseñó para Lima: el basamento, el pilar y la alegoría alada en su cara frontal, las alegorías voladoras del capitel. Sin embargo, en este caso el proyecto de Querol fue desechado en favor de la propuesta de José Grases Riera, que finalmente se ejecutó.

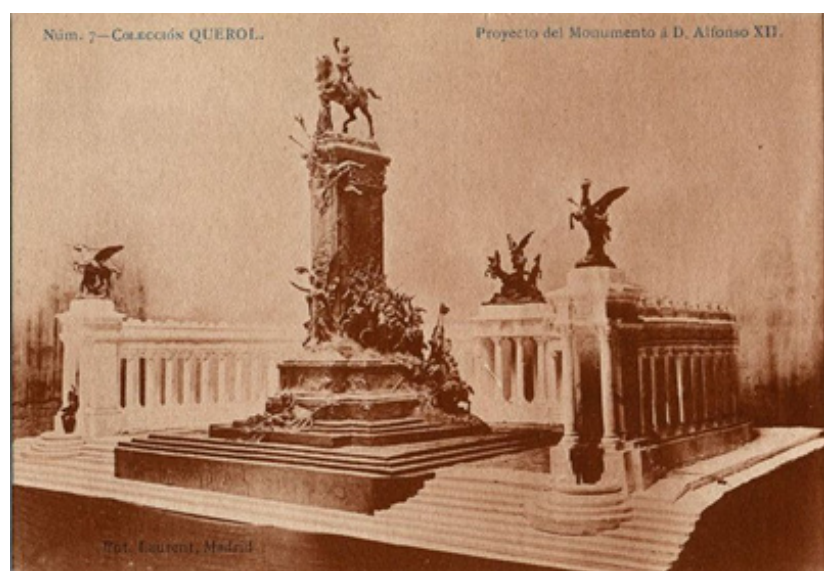

Figura 8. Proyecto de Querol para el Monumento a AlfonsoXII. http://www.memoriademadrid.es/buscador.php?accion=VerFicha\&id=31 270\&num_id=19\&num_total $=210$

Volviendo a la obra de Querol en Lima, la pieza principal fue cambiada en 1954 por otra de Artemio Ocańa. Ocurrió durante el gobierno de Manuel Odría, la bota militar decidió alterar el conjunto escultórico de acuerdo a los gustos oficiales de los jefes militares. Mario Vargas Llosa cuestionó el retiro de la pieza original en un artículo publicado en la revista Turismo. Aunque por defender a Querol se excedió con Ocańa:

De todo ese material recuerdo un texto, «En torno a una escultura", escrito en protesta por un acto de barbarie cometido por el ministro de educación de la dictadura —el general Zenón Noriega-, que ordenó retirar del grupo escultórico del monumento a Bolognesi (hecho por el español Agustín Querol) la bella estatua del héroe, pues su postura no le pareció heroica. Y en vez de la imagen del Bolognesi original - esculpido en el momento de caer acribilladohizo poner el grotesco monigote blandiendo una bandera que ahora afea el que era uno de los bonitos monumentos de Lima. (1993, p. 234). 
Es una estatua de cuerpo entero, de pie, de volumen abierto y movimiento dinámico. La luz incide desigualmente generando claroscuros. La trama geométrica es más compleja, con triángulos imaginarios que se superponen.

Sobre el morro de Arica se agiganta la figura del héroe, con la pierna izquierda sobre el peñón, la cabeza erguida, la mirada en el horizonte y la mano izquierda levantando la bandera nacional. La enseña sigue replegada en el asta, pero es menos ampulosa que en el bronce queroliano. Hay un cambio notable en el modelo de revólver —esta vez de mayor tamañocomo si se tratara de una masculinización simbólica. El uniforme es el mismo de la pieza original, pero no luce tantas arrugas, la superficie es más lisa. Mantiene los dos cordones del lado derecho. El arma blanca —en su vaina- cuelga del cinto y cae de manera vertical.

La nueva versión también es alegórica. Ocaña ha reinterpretado a Querol para lograr una versión más acorde con el gusto de los militares y del público en general. Pero el revólver en la mano derecha y la idea de la bandera asociada al jefe de Arica se mantienen. Es como si esta figura del héroe desafiante, mostrara el instante previo al Bolognesi herido de Querol.

\section{Contenido}

Para la ceremonia de inauguración del monumento, volvió al Perú Roque Sáenz Peña, militar argentino que voluntariamente combatió por nuestro país y fue herido en la batalla de Arica. Luchó al mando del batallón Iquique que pertenecía a la Octava División comandada por Alfonso Ugarte. Fue tomado prisionero cuando asumía el mando de la división ante la muerte del héroe iquiqueño.

$\mathrm{Al}$ enterarse de la inauguración del monumento, Sáenz Peña anunció su visita al Perú:

Roque Sáenz Peña.- Estudio.- Reconquista 144. Buenos Aires, julio 10.1905.

Señor J. Oyague y Soyer. Lima.

Distinguido señor amigo:

Usted ha mantenido con encomiable afecto el culto a la memoria del coronel Bolognesi, a quien la nación peruana, le debe toda su gratitud. La perseverancia en su admiración y culto por el héroe, recomiendan altamente su patriotismo, como sus sentimientos de justicia y es en ese carácter de presidente de la Asamblea Bolognesi que le dirijo la presente, poniendo en su conocimiento, que aun cuando no tengo recibido aviso de la inauguración del monumento, me considero como uno de los deudos de esas honras y demando mi pedazo de sol, entre las multitudes peruanas -que aclamarán al héroe en el día de su apoteosis.- He manifestado alguna vez, que donde quiera que vivan los soldados del coronel Bolognesi, deben trasladarse a Lima a presentarle las armas y rendirle el merecido tributo de su viejo cariño y admiración.

Debo, pues dar el ejemplo y cumplir con este voto de mi corazón. Seré con seguridad el sobreviviente más lejano del lugar de las honras; pero he resuelto suprimir la distancia y espero encontrarme en ese día con mis inválidos del batallón «Iquique», para confundirme con ellos, como amigo y camarada en la guarnición de Arica.

Mientras me doy el placer de estrechar a Ud. la mano, me reitero su afectísimo amigo y SS.

Roque Sáenz Peña. (Vargas, 1980, pp. 159-160).

Finalmente elaboró un conmovedor discurso para la inauguración, pensado como un diálogo entre él y su jefe, el héroe de bronce. De la fina pieza de oratoria - titulada La glorificación de Bolognesi- destacamos estos párrafos:

Mi coronel Bolognesi

Uno de tus capitanes vuelve de nuevo a sus cuarteles, desde la lejana tierra atlántica llamado por los clarines que pregonan tus hechos esclarecidos, desde el Pacifico hasta el Plata y desde el Amazonas hasta el seno fecundo del golfo de México [...]

Regreso con distancia de un cuarto de siglo, pero vuelvo sin olvidos y sin retardos, porque llego en la hora justa de tu apoteosis, que tampoco la posterga la lentitud de tu pueblo, ni trataron de omitirla las nuevas generaciones que recibieron bajo el casco guerrero de su progenitores el ósculo final de la partida, brindando las mezcladas sonrisas de la orfandad al culto perenne de la patria, a su defensa y a su integridad y si han sido necesarios cinco lustros para modelar tu efigie en la pasta candente de los inmortales, es porque los grandes hechos que consagran los pueblos agradecidos, deben ser definitivos, indiscutidos e infalibles, y este juicio solemne y supremo solo puede pronunciarlo la posteridad, porque la gloria es un fruto de lenta maduración, que no han de fecundarlo los mismos soles que le vieron florecer.

El monumento no ha llegado tardíamente, ha pasado el tiempo necesario para que el país comprenda a 
cabalidad la grandeza del acto heroico. Continúa hablando con el héroe y exalta sus virtudes:

Llegamos pues a honrar los actos que te dieron el renombre en la hora justa y en su momento histórico, cuando ya no gravitan sobre la tierra sino escasos eslabones de tu generación y pueden contarse sin esfuerzo los soldados inválidos de la epopeya, diseminados y dispersos como las tablas de la nave que desunió con furia la tempestad, para recomponerse sobre la playa hospitalaria en la mañana serena y en las horas del día que disipan y calman los huracanes. Son en efecto otros hombres los que me es dado mirar al pie de tu monumento, son otras fisonomías las que me estrechan la mano y me confunden en un abrazo popular y efusivo, a título de amigo tuyo, como si fuera el portador de tu palabra postrera, depositario de tu voluntad suprema, confidente o mensajero de tus anhelos y designios, pero aquí se encuentran todos tus sobrevivientes, que recibieron el ejemplo de tus virtudes cívicas, tus enseñanzas de honor militar y el deber austero y probo que consumó tu inmolación [...]

Y cierra con estas palabras:

\section{Coronel Bolognesi}

Tus sobrevivientes te saludan sobre el pentélico sagrado y somos tus sobrevivientes, porque la selección siniestra decapita la flor y no la yerba que ha de perecer también en el desgate común de las vegetaciones imperfectas, pero todos rodeamos tu monumento; y si he surcado dos piélagos para traerte la ofrenda de mi corazón, es porque tu noble patria tenía el derecho de exigir que no faltara a esta cita ninguno de tus soldados, y todos, todos los que vivimos hemos dejado caer de nuestras manos los instrumentos de trabajo y desandando camino sobre la prosa de la vida, venimos a refrescar en el recuerdo, que es la fuente de la juventud lejana, las horas gratas de tu dulce amistad y a sentir las emociones y regocijo de tu pueblo en esta fecha nacional, porque a los muertos ilustres no se lloran: se saludan, se aclaman y se veneran [...]. (Sáenz Реña, 1954, pp.17-21)

Pero la estatua que inspiró tan vibrante discurso no fue del agrado de todos. El mismo ańo de la inauguración, Manuel González Prada la cuestionó duramente en su texto "Nuestras glorificaciones», incluido en Horas de lucha (2003). No le gustó el exceso de figuras y adornos que oscurecen su sentido. Y enfiló su ataque contra las figuras aladas y la reiteración del nombre del artista:
¡Qué profusión de ellas! Parece que nos halláramos en un museo de Ornitología: hasta un caballo, muerto y en una posición escabrosa, más tiene de ave hidrópica y desplumada que de solípedo. Como invención y factura, no implicaría gran pérdida la eliminación de una mujer ocupada en señalar o escribir una fecha. ) ¿Quién es? ¿La hija o la viuda de Bolognesi? ¿La Historia, la Patria o solo una vocifératrice? No harían falta los bajorrelieves donde asoman figuras tiesas, apergaminadas, sin blanduras ni flexibilidades humanas, con parecido de objetos vaciados en un solo molde. En ninguna se siente circular la sangre, que todas semejan recortes de cartón, pegados en un muro y medio desprendidos por la humedad. Como en cada bajorrelieve leemos el nombre de Querol, les tomamos por hojas arrancadas a un diario de avisos. La Humanidad no sabe quiénes esculpieron la Venus de Milo y el grupo de Laocoón; pero las generaciones futuras no ignorarán quién hizo el monumento de Bolognesi.

Arremete contra la figura del héroe en la que encuentra mansedumbre y falta de virilidad. Reclama la necesidad de poner a la vista del pueblo monumentos que exalten la vida, porque a un pueblo que fue vencido y necesita levantar su autoestima no le sirven esculturas tristes, depresivas o lacrimosas. Pareciera que el héroe sale de una "francachela», duras palabras que servirían de argumento para que un gobierno militar cambiara la estatua.

La actitud de Bolognesi no expresa la resignación viril del militar que voluntariamente ofrenda su vida, sino la mansedumbre pasiva, la conformidad ovejuna. En vez del jefe herido y próximo a caer para no levantarse más, vemos al soldado que en día de francachela empuña el revólver del coronel, atrapa la bandera del batallón y va tambaleándose hasta rodar en tierra para dormir la crápula. Le vemos cómico y trágico, pues antes de ir al suelo, puede arrojar un tiro a cierta mujer que le brinda la imprescindible corona de laurel. ¡Infeliz Bolognesi! El plomo chileno le quitó la vida, el bronce queroliano le pone en irrisión.

\section{Comentario final}

En su accidentado devenir la joven república pasó por un proceso de independencia política sin mayor transformación social, el estrato criollo de la sociedad se puso al frente pero no tuvo clara la dirección a seguir, 
ni supo incorporar a los demás sectores sociales a su proyecto. El auge del guano pareció abrir la puerta a un futuro promisorio, pero la falta de conducción llevó a una crisis económica e internacional.

La victoria del 2 de mayo de 1866 encendió las luces patrióticas pero la derrota en la guerra del Pacífico desnudó todas nuestras falencias sociales, políticas y geopolíticas. Sobre las ruinas humeantes de la guerra empezó a construirse la nación. Los modelos a seguir serían lo héroes derrotados en la conflagración. Vencidos, pero héroes de todas maneras.

Los monumentos escultóricos ubicados en las plazas de la ciudad cuentan el pasado a través de los discursos oficiales de nuestra convulsionada historia. Y Lima es generosa en este género escultórico (Castrillón 1991; Crousse 2011; Gamarra Puertas 1974, 1996; Gutiérrez Viñuales 2003a; Majluf 1994; Mayer y Leonardini 2000; Quijano 2003).

Emilio Tarazona señala que la función principal de un monumento

[...] consiste en fijar, en cierta medida, una reminiscencia del pasado para el presente o la posteridad, construyendo un símbolo memorable y produciendo una ruptura momentánea del transcurso ordinario de los sucesos, capaz de alterar radicalmente la opresiva ansiedad de vivir en un tiempo cualitativamente nulo, sin instantes significativos ni sucesos relevantes. (2003, pp. 163-164).

Nuestro tiempo "cualitativamente nulo» se ve transmutado en la contemplación de obras de arte que hablan de un pasado heroico y/o memorable. Y en toda Latinoamérica tuvimos una fiebre de monumentos conmemorativos que expresaban los ideales de las jóvenes repúblicas. Tal como explican Flavia Frigeri y Sharon Lerner:

A comienzos del siglo XX un nuevo fenómeno de redecoración urbana, inspirado en las tradiciones occidentales, se extendió por toda América Latina. Los monumentos tomaban las plazas y los espacios públicos con el objetivo de fomentar un sentimiento de identidad nacional, emplazamientos que pronto se convertirían en la manifestación más evidente del proceso de unificación promovido por las nacionesestados. (2013).

Redecoración urbana que no se queda en lo decorativo, es un lenguaje de símbolos en favor de la unificación nacional. Los hombres que "hacen la Patria» pasan a ser inmortalizados en el bronce o el mármol, en los frágiles proyectos nacionales que las élites ensayan. Esto, por supuesto, no mella en nada la figura de algunos de estos hombres que tuvieron conductas realmente heroicas o excepcionales.

Sin embargo, la situación actual de muchos monumentos conmemorativos es lamentable. Despierten poco interés en el hombre de a pie, cosa que es fácil de constatar al pasar unas horas en el entorno de las esculturas. Y cuando atraen la mirada de las autoridades los resultados son generalmente intervenciones desafortunadas.

Otros autores ha anotado que estas esculturas ya no corresponden a nuestro tiempo, por eso sus significados otrora colectivos, han devenido en asunto de comunidades específicas, sobre todo instituciones militares. En ese sentido Rodrigo Quijano afirma:

La antigua red de símbolos patrios y sus rituales de conmemoración republicanos en las plazas, estatuas y avenidas está constituida desde hace mucho por fósiles monumentales que reposan pacientemente contra el horizonte a la espera inevitable del olvido o de algo que inesperadamente los devuelva a la vida. (2013).

Lima es una ciudad con un interesante acervo de escultura pública monumental, que en los últimos años ha sido afectado por acciones -e inacciones- de las autoridades que deberían protegerlo y promocionarlo. Desde el abandono total, pasando por intervenciones distorsionadoras de los diseños originales, hasta el atentado directo destructivo, el Estado se ha convertido en el enemigo número uno del arte escultórico. Muchas autoridades pasan por alto el buen criterio y normas como la siguiente: «La política de mobiliario urbano debe tender a satisfacer las necesidades de los transeúntes en cuanto a orientación, higiene, recreación, etc. Asimismo debe realzar las calidades estéticas de los monumentos y ambientes urbano monumentales» (Reglamento de la Administración del Centro Histórico de Lima. Ordenanza 062. Artículo 11).

En el caso del monumento a Bolognesi son evidentes una serie de daños, a saber: Cambio de una pieza original, mutilaciones en las piezas de bronce (las armas blancas), aplicación de pintura negra sobre el bronce, pintura verde sobre el pedestal de roca y pintura negra sobre el basamento de roca, invasión de 
felinos y cucarachas, entorno arquitectónico derruido en la Av. Arica.

La restauración total del monumento a Bolognesi debe incluir la reposición de la pieza original actualmente en la Fortaleza del Real Felipe. En cuanto a la obra de Ocańa — que también es de gran calidadpuede ser trasladada a la Plaza de la Bandera (Cabanillas 2009; 2015).

La escultura estudiada y otras similares son obras de arte valiosas por sí mismas, que deben ser recuperadas y puestas en valor. Recuperar su diseño formal original nos permitirá entender mejor su rico contenido moral, cívico y patriótico.

\section{Referencias bibliográficas}

Cabanillas, Virgilio Freddy (2015). La destrucción oficial del patrimonio escultórico de Lima. Recuperado de https://peruanticuario.wordpress.com/2015/06/13/ladestruccion-oficial-del-patrimonio-escultorico-de-lima/

Cabanillas, Virgilio Freddy (2009) Monumental descuido. Memoria, arte y ciudad. Hexágono. Revista del Colegio de Arquitectos del Perú. Año 1 (3), 48-53.

CAstrillón, Alfonso (1991). Escultura monumental y funeraria en Lima. Recuperado dehttp://www.urp. edu.pe/urp/modules/institutos/invest_mus/escul_ monufune.pdf

Crousse, Verónica (2011). Reencontrando la espacialidad en el arte público del Perú (Tesis doctoral). Programa de Doctorado (EEES) Espacio Público y Regeneración Urbana: Arte, Teoría y Conservación del Patrimonio. Universidad de Barcelona. Recuperado de http://www. tdx.cat/handle/10803/1551

Frigeri, Flavia y Sharon Lerner (2013). Ruinas al revés. Lima: Museo de Arte. [Exposición realizada del 7 de agosto al 10 de noviembre de2013].

Gamarra Puertas, José Antonio (1996). Obras de arte y turismo monumental. Bronces ecuestres - estatuas (de pie y sentadas). Bustos - obeliscos. Lima: Edición del autor.

Gamarra Puertas, José Antonio (1974). Historia y odisea de monumentos escultóricos conmemorativos. Lima: Edición del autor.

González Prada, Manuel (2003). Horas de lucha. Edición de Thomas Ward. Recuperado de http://evergreen.loyola. edu/tward/www/gp/libros/horas/

Gutiérrez Viñuales, Rodrigo (2003a). Monumentos conmemorativos de escultores españoles en Iberoamérica (1897-1926). En: Cabańas Bravo, Miguel (coord.). Elarte español fuera de España (pp. 355-366). Madrid: Consejo Superior de Investigaciones Científicas. Recuperado de http://www.ugr.es/ $\sim$ rgutierr/PDF1/079.pdf

GutiérreZ Viñuales, Rodrigo (2003b). El papel de las artes en la construcción de las identidades nacionales en Iberoamérica. Historia Mexicana, vol. LIII, núm. 2, pp. 341- 390. Recuperado dehttp://www.ugr.es/-rgutierr/ PDF1/070.pdf

Hamann, Johanna (2011). Monumentos públicos en espacios urbanos de Lima. 1919- 1930 (Tesis doctoral). Programa de Doctorado (EEES) Espacio Público y Regeneración Urbana: Arte, Teoría y Conservación del Patrimonio. Universidad de Barcelona. Recuperado de http://www. johannahamann.com/wp-content/uploads/2013/03/ Monumentos-Publicos-en-Espacios-Urbanos-deLima-1919-1930-Tesis-doctoral-presentada-para-ladefensa-del-grado-de-doctor-enero-2011-Universidadde-Barcelona-Johanna-Hamann-Mazure.pdf

Majluf, Natalia (1994). Escultura y espacio público. Lima, 1850-1879. Lima: Instituto de Estudios Peruanos (Documento de Trabajo N. 67).

Mayer, Elzinha y Nanda Leonardini (2000). Guía NANDEL. Lima-Callao. Lima: Rubicán Editores.

Quijano, Rodrigo (2013). Horizontes compartidos. En: Lima 04. Lima: Museo de Arte Contemporáneo. [Exposición realizada del 24 de enero al 7 de abril de 2013].

Quijano, Rodrigo (2003). Tierra baldía y parques de identidad: notas sobre escultura, monumento y espacio público en el Perú en el cambio de siglo. En: Homenaje a Anna Maccagno. I Simposio sobre la escultura peruana del siglo XX (pp. 193-201). Lima: PUCP.

Sáenz Peña, Roque (1954). La glorificación de Bolognesi. En: Evaristo San Cristóval. Semblanza del General Roque Sáenz Peña. Lima: Ministerio de Guerra.

Tarazona, Emilio (2003). Iniciativas de monumentalidad y rituales de conmemoración: un enfoque programático del no objetualismo en el Perú. En: Homenaje a Anna Maccagno. I Simposio sobre la escultura peruana del siglo XX (pp. 163-179). Lima: PUCP.

Tipian, Daniel (2016). Monumento de Querol a Francisco Bolognesi (entrevista). Recuperado de http:// programaumbrales.blogspot.pe/2016/06/entrevistadaniel-tipian-monumento-de.html

Vargas Hurtado, Gerardo (1980). La batalla de Arica. 2a ed. Lima: Comisión Nacional del Centenario de la Guerra del Pacífico (Colección Documental de la Historia del Perú1879-1884).

Vargas Llosa, Mario (1993). El pez en el agua. Barcelona: Seix Barral. 